\title{
Identification of a Novel Chlorinated Fatty Acid from the Marine Rhodopirellula baltica
}

\author{
Yeon-Ju Lee, Jong Wook Lee, Chulhong Oh, ${ }^{\dagger}$ Soo-Jin Heo, ${ }^{\dagger}$ Do-Hyung Kang, ${ }^{\dagger}$ Hee Jae Shin, and Hyi-Seung Lee ${ }^{*}$ \\ Marine Natural Products Laboratory and ${ }^{\dagger}$ Marine Living Resources Research Department, \\ Korea Ocean Research \& Development Institute, Ansan 426-744, Korea. *E-mail: hslee@kordi.re.kr \\ Received July 23, 2010, Accepted September 6, 2010
}

Key Words: Rhodopirellula baltica, Chlorinated fatty acid, Tyrosinase inhibition

\begin{abstract}
Rhodopirellula baltica is an attached-living marine bacterium spending most of their lifetime attached on the surface of other marine organisms or organic aggregates. As a general technique to isolate the new strains of attached-living bacteria is not yet available, ${ }^{1}$ genomic and proteomic information of this species which revealed the presence of useful proteins such as enzymes important for the metabolism of sulfated carbohydrates was obtained only recently. ${ }^{2}$ Secondary metabolites produced by $R$. baltica, however, have never been investigated probably due to the difficulties in its cultivation.

During the course of our search for biologically active constituents from tropical marine organisms, ${ }^{3}$ we have encountered a colonized cluster of $R$. baltica attached to the surface of the brown algae, Pylaiella littoralis in the Federated States of Micronesia. Directed by the results of ${ }^{1} \mathrm{H}$ NMR analyses, the crude extract was separated by solvent partitioning followed by reversed-phase vacuum flash chromatography and $\mathrm{C}_{18}$ HPLC to afford two secondary metabolites. Herein, we describe the isolation and structure elucidation of a new chlorinated fatty acid (1) along with a known malyngic acid (2) (Figure 1).
\end{abstract}

Frozen specimens of $R$. baltica attached on the surface of $P$. littoralis were extracted with $\mathrm{MeOH}$ and $\mathrm{CH}_{2} \mathrm{Cl}_{2}$. The combined extract was partitioned between $n-\mathrm{BuOH}$ and $\mathrm{H}_{2} \mathrm{O}$. The butanol layer was dissolved in $15 \%$ aqueous $\mathrm{MeOH}$ and extracted with hexane. Further separations of the methanol layer by ODS columns, followed by reversed-phase HPLC, afforded two fatty acids. Compound $\mathbf{1}$ was obtained as a colorless oil, of which the negative LRESIMS showed two molecular ion peaks at $\mathrm{m} / \mathrm{z}$ 215.19 and $\mathrm{m} / \mathrm{z} 217.23$ suggesting the presence of a chloride in the structure. The molecular formula $\mathrm{C}_{11} \mathrm{H}_{17} \mathrm{ClO}_{2}$ was established based on a combination of HREIMS and ${ }^{13} \mathrm{C}$ NMR spectrometry. Several characteristic features of the unsaturated fatty acid appeared in the ${ }^{1} \mathrm{H}$ NMR spectral data, which showed the presence of a terminal methyl group ( $\delta 0.92)$, five methylenes

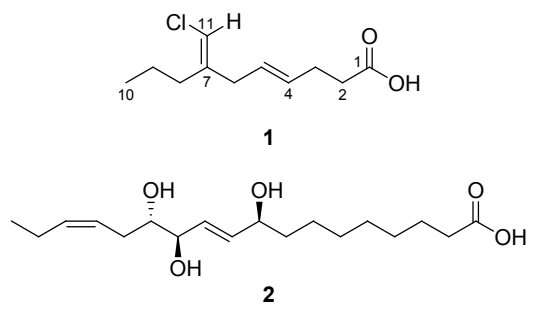

Figure 1. Chemical structures of $\mathbf{1}$ and $\mathbf{2}$. $(\delta 1.45,2.18,2.30,2.34$ and 2.76$)$, a disubstituted double bond ( $\delta 5.43$ and 5.53), and an additional olefinic proton $(\delta 5.89)$ (Table 1). The corresponding carbon signals were observed in the ${ }^{13} \mathrm{C}$ NMR spectra, which showed the presence of a methyl group $(\delta 14.2)$, five methylenes $(\delta 21.2,28.9,33.0,34.9$ and $38.8)$, two double bonds ( $\delta 114.1,130.6,134.1$ and 142.9), and an additional carbonyl $(\delta 176.9)$ carbon. The structure of $\mathbf{1}$ was elucidated further by $2 \mathrm{D}$ NMR experiments. In the ${ }^{1} \mathrm{H}-{ }^{1} \mathrm{H}$ COSY experiment, the methylene proton signal at $\delta 1.45$ showed correlations with the methyl signal at $\delta 0.92$ and the methylene signal at $\delta 2.18$. The olefinic proton signals at $\delta 5.43$ and 5.53 showed correlations with the methylene signals at $\delta 2.76$ and 2.30, respectively. A combination of the HSQC and HMBC data allowed assignments of the characteristic ${ }^{13} \mathrm{C}$ NMR signals, and the key HMBC correlations from $\mathrm{H}-11\left(\delta_{\mathrm{H}} 5.89\right)$ to C-6, C-7, and $\mathrm{C}-8$ and from $\mathrm{H}-3\left(\delta_{\mathrm{H}} 2.30\right)$ to $\mathrm{C}-1\left(\delta_{\mathrm{C}} 176.9\right)$ confirmed the location of chloroalkene group and carboxylic acid units (Figure 2).

The geometry of the chloroalkene residue was determined by the measurement of vicinal ${ }^{13} \mathrm{C}-{ }^{1} \mathrm{H}$ coupling constants. It was probable that the geometry of the double bond between $\mathrm{C}-7$

Table 1. NMR Data (500 MHz, $\left.\mathrm{CD}_{3} \mathrm{OD}\right)$ for 1

\begin{tabular}{ccll}
\hline Position & $\delta_{\mathrm{C},}$, mult & \multicolumn{1}{c}{$\delta_{\mathrm{H}}(J$ in $\mathrm{Hz})$} & $\mathrm{HMBC}^{a}$ \\
\hline 1 & $176.9, \mathrm{C}$ & & \\
2 & $34.9, \mathrm{CH}_{2}$ & $2.34, \mathrm{t}(6.0)$ & $1,3,4$ \\
3 & $28.9, \mathrm{CH}_{2}$ & $2.30, \mathrm{q}(6.0)$ & $1,2,4,5$ \\
4 & $132.4, \mathrm{CH}$ & $5.53, \mathrm{dt}(15.1,6.0)$ & \\
5 & $129.0, \mathrm{CH}$ & $5.43, \mathrm{dt}(15.1,6.8)$ & \\
6 & $38.8, \mathrm{CH}_{2}$ & $2.76, \mathrm{~d}(6.8)$ & $4,5,7,8$ \\
7 & $142.9, \mathrm{C}$ & & \\
8 & $33.0, \mathrm{CH}_{2}$ & $2.18, \mathrm{t}(7.6)$ & $6,7,9,10$ \\
9 & $21.2, \mathrm{CH}_{2}$ & $1.45, \mathrm{tq}(7.6,7.3)$ & $7,8,10$ \\
10 & $14.2, \mathrm{CH}_{3}$ & $0.92, \mathrm{t}(7.3)$ & 8,9 \\
11 & $114.1, \mathrm{CH}^{2}$ & $5.89, \mathrm{~s}$ & $6,7,8$ \\
\hline${ }^{a} \mathrm{HMBC}$ correlations are from proton(s) stated to the indicated carbon.
\end{tabular}

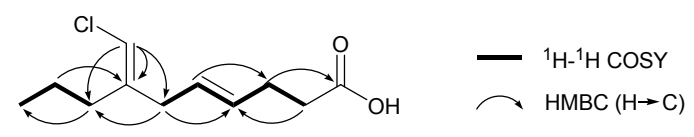

Figure 2. Key ${ }^{1} \mathrm{H}-{ }^{1} \mathrm{H}$ COSY and $\mathrm{HMBC}$ interactions of $\mathbf{1}$. 


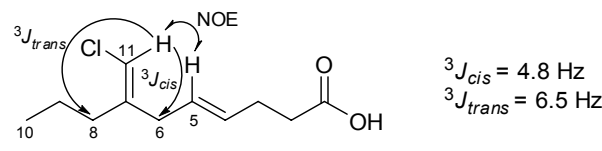

Figure 3. Comparison of ${ }^{1} \mathrm{H}^{13} \mathrm{C}$ couplings in $\mathbf{1}$.

and C-11 might be trans as a weak NOE interaction between the olefinic proton (H-5) and the proton germinal to the chloride (H-11) was observed. To figure out the geometry clearly, three bond ${ }^{13} \mathrm{C}$ - ${ }^{1} \mathrm{H}$ coupling constants $\left({ }^{3} J_{\mathrm{CH}}\right)$ from a ${ }^{1} \mathrm{H}$-coupled ${ }^{13} \mathrm{C}$ NMR experiment were examined. The J-HMBC spectrum of 1 showed two couplings, i.e., ${ }^{3} J_{\mathrm{CH}}=6.5 \mathrm{~Hz}$ from C-8 to H-11 and ${ }^{3} J_{\mathrm{CH}}=4.8 \mathrm{~Hz}$ from C-6 (Figure 3 ). This result unambiguously demonstrated a trans relationship between C-8 and H-11, as it is known that the numerical values of the trans coupling constants ${ }^{3} J_{\mathrm{CH}}$ are higher than those of the cis coupling constants. ${ }^{4,5,6}$ The disubstituted alkene between C-4 and C-5 had an $E$ configuration, as confirmed by the ${ }^{1} \mathrm{H}-{ }^{1} \mathrm{H}$ vicinal coupling constant for the olefinic protons $(J=15.1 \mathrm{~Hz})$. On the basis of these results described above, 1 was determined to be $(4 E, 7 E)$ 7-(chloromethylene)dec-4-enoic acid, which is reported for the first time.

Compound 2, a more polar constituent, was obtained as a pale-yellow gum. On the basis of the results of combined spectroscopic analyses, it was confirmed that $\mathbf{2}$ has a structure identical to that of malyngic acid, which was previously reported as a bioactive secondary metabolite of the marine blue-green alga Lyngbya majuscula. ${ }^{7}$ Spectral data of $\mathbf{2}$ were in good agreement with those reported previously. The inhibitory activity of 1 against mushroom tyrosinase was examined to result in a $43 \%$ reduction in enzyme activity at a concentration of $200 \mu \mathrm{g} / \mathrm{mL}$.

\section{Experimental Section}

General procedures. The ${ }^{1} \mathrm{H}$ NMR spectra were recorded on a Variant Unity 500 spectrometer at $500 \mathrm{MHz}$ and ${ }^{13} \mathrm{C} \mathrm{NMR}$ spectra were also recorded on the same instrument at $125 \mathrm{MHz}$. Chemical shifts were reported on a $\delta$ (ppm) scale with the solvent resonance resulting from incomplete deuteration of $\mathrm{CD}_{3} \mathrm{OD}$ $\left({ }^{1} \mathrm{H}, 3.30 \mathrm{ppm} ;{ }^{13} \mathrm{C}, 49.0 \mathrm{ppm}\right)$ as the internal reference. The NOE and J-HMBC experiments were performed with Bruker Avance 800 spectrometer. Mass spectra were taken with a Micromass Auto Spec spectrometer. HPLC was performed with an YMC Pack Pro $\mathrm{C}_{18}$ column $(250 \times 10 \mathrm{~mm}, 5 \mu \mathrm{m}$, and $80 \AA)$ using a Shodex RI-101 detector.

Collection and taxonomic identification. The bacterial cluster attached on the brown algae was collected by Dr. D.-H. Kang at a depth of 3 - $5 \mathrm{~m}$ from Chuuk Atoll, Federated States of Micronesia, in July 2009, and was identified by Dr. C. Oh on the basis of genetic analysis, including the comparison of $16 \mathrm{~S}$ rRNA gene. A voucher specimen (Registry No. 09CH-101) has been deposited at the Marine Bio-Research Center, Korea Ocean Research \& Development Institute, Korea.

Extraction and isolation. A colonized cluster of $R$. baltica was immediately frozen and maintained at $-25^{\circ} \mathrm{C}$ until investigated chemically. The specimens were lyophilized (dry wt $70.3 \mathrm{~g})$ and repeatedly extracted with $\mathrm{MeOH}(300 \mathrm{~mL} \times 2)$ and $\mathrm{CH}_{2} \mathrm{Cl}_{2}(300 \mathrm{~mL})$. The extract was filtered and concentrated under reduced pressure to afford $14.1 \mathrm{~g}$ of the crude extract. The residue was partitioned between $\mathrm{H}_{2} \mathrm{O}$ and $n-\mathrm{BuOH}$ to yield $3.5 \mathrm{~g}$ of an organic-soluble material. The $n-\mathrm{BuOH}$ layer was repartitioned between $15 \%$ aqueous $\mathrm{MeOH}(2.3 \mathrm{~g})$ and $n$-hexane $(1.0 \mathrm{~g})$. The residue of the aqueous $\mathrm{MeOH}$ layer was subjected to $\mathrm{C}_{18}$ reversed-phase flash chromatography using a gradient mixture of $\mathrm{MeOH}$ and $\mathrm{H}_{2} \mathrm{O}$.

The fraction eluted with $20 \%$ aqueous $\mathrm{MeOH}$ was dried (70 mg) and separated by reversed-phase HPLC (YMC Pack Pro $\mathrm{C}_{18}$ column, $30 \%$ aqueous $\mathrm{MeOH}$ ) to afford $9.6 \mathrm{mg}$ of pure 1 as a major product. The fraction eluted with $30 \%$ aqueous $\mathrm{MeOH}$ (33 mg) was separated by reversed-phase HPLC (YMC Pack Pro $\mathrm{C}_{18}$ column, 55\% aqueous $\mathrm{MeOH}$ ) to yield $1.9 \mathrm{mg}$ of 2 .

(4E,7E)-7-(Chloromethylene)dec-4-enoic acid (1): Colorless oil; IR (neat) $v_{\max } 3436,2960,1737,1629,1438,1199 \mathrm{~cm}^{-1} ;{ }^{1} \mathrm{H}$ and ${ }^{13} \mathrm{C}$ NMR data, see Table 1; LRESIMS $m / z$ 215.19, 217.23 [M-H] ; HREIMS $m / z 216.0919[\mathrm{M}]^{+}$(calcd for $\mathrm{C}_{11} \mathrm{H}_{17} \mathrm{ClO}_{2}$, 216.0917).

$(9 S, 12 R, 13 S)$-Trihydroxyoctadeca-(10E,15Z)-dienoic acid (2): Pale-yellow gum; $[\alpha]_{\mathrm{D}}^{25}+10.2^{\circ}(c 0.04, \mathrm{MeOH}),\left[\text { Lit. }+7.5^{\circ}\right]^{7}$; LRESIMS $m / z$ 329.51 [M+H] .

Inhibitory effect of mushroom tyrosinase. The inhibitory activity of tyrosinase was performed according to the method of Vanni et al., ${ }^{8}$ with minor modifications. The reaction mixture contained $140 \mu \mathrm{L}$ of $0.1 \mathrm{M}$ phosphate buffer ( $\mathrm{pH} 6.5), 40 \mu \mathrm{L}$ of $1.5 \mathrm{mM}$ L-tyrosine, and $10 \mu \mathrm{L}$ of compound. Then, $10 \mu \mathrm{L}$ of mushroom tyrosinase $(2,100$ units $/ \mathrm{mL})$ solution was added, and the reaction was incubated at $37{ }^{\circ} \mathrm{C}$ for $12 \mathrm{~min}$. After incubation, the amount of dopachrome produced in the reaction mixture was determined by carrying outoptical density at $490 \mathrm{~nm}$ in a microplate reader.

Acknowledgments. We are grateful to the Department of Marine Resources, State of Chuuk, Federated States of Micronesia, for supporting marine organism research. The NOE and J-HMBC spectral data were kindly provided by Ms. E. H. Kim, Korea Basic Science Institute, Ochang, Korea. This research was partially supported by the Korea Ocean Research and Development Institute (PE98472), and the Ministry of Land, Transport and Maritime Affairs, Korea (PM55421).

\section{References}

1. Winkelmann, N.; Harder, J. J. Microbiol. Methods 2009, 77, 276.

2. Wagner, M.; Horn, M. Curr. Opin. Biotech. 2006, 17, 241.

3. Lee, H.-S.; Yoon, K.-M.; Han, Y.-R.; Lee, K. J.; Chung, S.-C.; Kim, T.-I.; Lee, S.-H.; Shin, J.; Oh, K.-B. Bioorg. Med. Chem. Lett. 2009, 19, 1051.

4. Ito, S.; Ziffer, H.; Bax, A. J. Org. Chem. 1986, 51, 1130.

5. Vogeli, U.; Philipsborn, W. Org. Magn. Reson. 1975, 7, 617.

6. Durow, A. C.; Butts, C.; Willis, C. L. Synthesis 2009, 17, 2954.

7. Cardellina, J. H., II.; Moore, R. E. Tetrahedron 1980, 36, 993.

8. Vanni, A.; Gastaldi, D.; Giunata, G. Ann Chim 1990, 80, 35. 